Josefino G. Hernandez, MD Department of Otorhinolaryngology College of Medicine - Philippine General Hospital University of the Philippines Manila
Correspondence: Josefino G. Hernandez, MD

Department of Otorhinolaryngology

Ward 10, Philippine General Hospital

Taft Ave., Ermita, Manila 1000

Phone (632) 526-4360

Fax (632) 525-5444

Reprints will not be available from the author.

No funding support was received for this study. The author signed a disclosure that he has a financial association with One Pharma, distributors of nasal saline $0.65 \%$ and $2.3 \%$ solutions $\left(\mathrm{SNIF}^{\mathrm{TM}}\right)$.

\section{Nasal Saline Irrigation for Sinonasal Disorders}

Nasal saline irrigation is a simple easy-to-do procedure that has been used to treat sinus and nasal conditions for many years. Wingrave in his 1902 paper "The Nature of Discharges \& Douches" discussed cleansing of the nasal passages as an important method of treating different nasal illnesses in the last part of the $19^{\text {th }}$ century. 'Nasal saline irrigation has been used for such sinonasal conditions as atrophic rhinitis, rhinosinusitis and allergic rhinitis, among infants with nasal problems and patients who have undergone endoscopic sinus surgery. Past recommendations for use were based on anecdotal evidence such as reports of patients living near the sea, whose symptoms improved with natural seawater irrigation while swimming.

The past two decades saw studies undertaken to support what has been in practice for many years. Taccariello studied 40 patients suffering from chronic sinusitis with 19 patients receiving traditional alkaline nasal douche and 21 patients receiving sterile sea water spray. Results showed that compared to the control group who received no treatment, douching per se improved endoscopic appearance and quality of life scores. ${ }^{2}$ Georgitis compared the use of nasal hyperthermia versus saline irrigation in patients with allergic rhinitis. Histamine levels fell with both forms of treatment with greatest declines seen with irrigation. Leukotriene C4 levels were significantly reduced by irrigation. ${ }^{3}$

Pediatricians have refrained from using oral and topical decongestants among infants. Excessive use of oral decongestants can result in cardiovascular side effects, while excessive use and sufficient absorption of topical decongestants can result in possible complications of CNS depression leading to coma and marked reduction in body temperature, especially in infants in whom these drugs should not be used. ${ }^{4} \mathrm{Nasal}$ saline irrigation has become a good alternative.

Another common use follows endoscopic sinus surgery, when the nasal cavity quickly becomes encrusted, and frequent cleaning and saline irrigation are needed for 4-8 weeks until the lining of the nose and sinuses has regenerated. ${ }^{5}$ Nasal saline irrigation moisturizes the nasal cavity and reduces dryness of the nasal mucosa. It has become important in clearing nasal crusts and thick mucous in patients with rhinosinusitis and has been known for its beneficial effect among patients with sinonasal problems.

Saline solutions can be classified into isotonic or hypertonic, buffered or non-buffered. Preparations include powder, spray or mist forms; with and without preservative; and with and without dispenser. The number of available products in the market can make it difficult for the doctor to decide on what product to recommend for his suffering patient, ranging from inexpensive home-made preparations to very expensive imported solutions. Different studies will be presented which may help in this choice.

\section{Isotonic or hypertonic solution}

The main issue at hand is whether to use an isotonic or hypertonic solution. Traissac from the University ENT Hospital - Bordeaux, in a study of 410 patients using isotonic solution, showed the beneficial action on the nasal sinus mucosa in medical disease and after sugery. ${ }^{6}$

Philipp J Otolaryngol Head Neck Surg 2007; 22 (1,2): 37-39

(C) Philippine Society of Otolaryngology - Head and Neck Surgery, Inc. 


\section{PRACTICE PEARLS}

Tomooka (University of California, 2000) in a study of 211 patients using hypertonic saline solution, showed improvement in 23 of the 30 symptoms queried. ${ }^{7}$

Talbot, in 1997, demonstrated among 21 volunteers that 3\% hypertonic saline solution decreased mucociliary saccharine transit times more than $0.9 \%$ normal saline, 3.1 minutes compared to 0.14 minutes less than baseline. ${ }^{8}$ This study was corroborated by Keojampa in 2004, demonstrating that buffered hypertonic saline improved saccharine clearance time more than buffered normal saline. ${ }^{9}$ Hypertonic saline solution decreases the viscosity of mucus which could have improved saccharine clearance time. However, it has been suggested that the saccharin dissolution method provides a less accurate assessment of mucociliary clearance against tagged insoluble particles, as the saccharin mixes between sol and gel layers of the mucociliary blanket and is not carried solely in the superficial gel layer. ${ }^{8}$

Boek from the University Hospital Utrecht studied the effect of different saline solutions on the ciliary beat frequency (CBF) of cryopreserved mucosa of the sphenoidal sinus measured by a photoelectric method. Results revealed that Locke-Ringer's solution (LR) had no effect on the $\mathrm{CBF}, \mathrm{NaCl} 0.9 \%$ had a moderately negative effect, $\mathrm{NaCl} 7 \%$ solution led to complete ciliostasis within five minutes (reversible after rinsing with LR), and $14.4 \%$ hypertonic solution had an irreversible ciliostatic effect. He concluded that LR is an isotonic solution with no effect on ciliary beat frequency. ${ }^{10}$ Therefore, it is probable that this solution is more appropriate than saline for nasal irrigation or antral lavage. This was further supported by the study of Min YG published in 2001, wherein isotonic and hypotonic solutions did not decrease ciliary beat frequency, but where ciliostasis was observed within a few minutes in the $3.0 \%$ and $7.0 \%$ solutions. ${ }^{11}$ Histologic changes showed disruption of nasal epithelial cells in vitro which could have resulted in decrease ciliary beat frequency in hypertonic solutions.

\section{Buffered or non-buffered solution}

The effect of $\mathrm{pH}$ on the rate of mucociliary clearance of the douching solution was also studied. One group was given hypertonic solution buffered to $\mathrm{pH} 8$ and another group given non-buffered hypertonic solution. ${ }^{12}$ Results showed no difference in mucociliary clearance between solutions buffered to $\mathrm{pH} 8$ and that which is non-buffered. ${ }^{12}$ In his paper, Taccariello noted that alkaline nasal douche improved endoscopic appearance but not the quality of life score, while sea water spray showed improved quality of life but not endoscopic appearance. $^{2}$

\section{Preparations}

Preparations for nasal saline irrigation in the market include powder which can be freshly prepared for use or ready-to-use spray or mist solutions which need preservatives to extend shelf life. Common preservatives are benzalkonium chloride, polyethylene glycol and propylene glycol. Bezalkonium chloride is an antibacterial preservative which may be potentially toxic to the mucosa.

Krayenbuhl and Seppey (1995) compared application of a saline stream versus drops (passive saline instillation) among 104 patients who underwent intranasal surgeries. Stream patients required significantly fewer post-operative recovery days and visits to physicians. The recovery period with saline stream was 18.9 days versus 36.7 days using saline drops. ${ }^{5}$

Nasal saline preparations available in the local market include isotonic drops, isotonic and hypertonic sprays, and isotonic seawater sprays. Parsons in 1996 presented a recipe for patients to prepare their own nasal saline solution: ${ }^{8}$

Carefully clean and rinse a 1-quart glass jar. Fill the
jar with tap water. Add 2 to 3 heaping teaspoons of
"pickling/canning" salt. Add 1 rounded teaspoon
of baking soda (pure bicarbonate). Stir and shake
well before use. Store at room temperature.

This will result in a $3 \%$ saline solution buffered to $\mathrm{pH} 7.6$. If the mixture is too strong and results in a stinging effect in the nose, less salt (1 1 1 tsp of salt) can be used. For children, it is best to start with a weaker salt water mixture which can be gradually increased in tonicity. Ordinary rock salt is used since iodine in iodized salt can be toxic to the nasal mucosa. A soft plastic catsup container can be used as a dispenser. The nose can be liberally irrigated 2-3 times per day. Nasal saline irrigation has been safely used by both children and adults with no documented serious side effects.

Different studies have shown that both isotonic and hypertonic nasal saline irrigations have beneficial effects in many sinonasal conditions. The exact mechanism by which improvement is effected is unclear.? Hypotheses for why nasal saline irrigation promotes improvement of nasal symptoms include the following:

1. improving mucociliary clearance

2. decreasing mucosal edema

3. decreasing inflammatory mediators

4. mechanically clearing nasal crusts and thick mucous

The choice of which nasal saline solution to use depends on the physician and is mainly based on which studies he or she will believe in. Whether to recommend a saline solution prepared by the patient at home or saline solutions that are commercially available is really up to the doctor. Commercial solutions have the advantage of being sterile. Saline prepared at home is cheaper, but sterility may not be guaranteed and the percentage of tonicity may be variable.

Although several studies have shown that hypertonic saline solutions improve saccharine transit time, other studies have likewise shown that hypertonic saline solutions affect ciliary beat frequency negatively. For 
PRACTICE PEARLS

this reason, isotonic saline solutions which do not affect ciliary beat frequency may be more appropriate than hypertonic saline solution for nasal irrigation. However, we cannot discount the mucolytic effect induced by the hyperosmolarity of hypertonic solutions which could have improved saccharine transit time. Further studies can be undertaken to finally determine which solution, isotonic or hypertonic, would be better to use as nasal saline irrigation for the different sinonasal disorders.

\section{REFERENCES}

1. Wingrave W. The nature of discharges and douches. The Lancet. 1902 May:1373-1375.

2. Taccariello M, Parikh A, Darby Y, Scadding G. Nasal douching as a valuable adjunct in the management of chronic rhinosinusitis. Rhinology 1999; 37:29-32.

3. Georgitis GW. Nasal hyperthermia and simple irrigation for perennial rhinitis: changes in inflammatory mediators. Chest 106:1487, 1994.

4. Goodman Gilman A, Goodman LS, RallTW, Murad F. Goodman and Gilman's The Pharmacological Basis of Therapies. th $^{\text {th }}$ ed., New York: Macmillan Publishing Co.;1985.

5. Papsin B, McTavish A. Saline nasal irrigation: its role as an adjunct treatment. Canadian Family Physician 2003; 49:168-173.

6. Traissac L, et al. Nasal washing with Physiomer... 10 years later: 1988-1998. Rev Laryngol Otol Rhinol (Bord) 1999; 120(2):133-135.

7. Tomooka L, Murphy C, Davidson T. Clinical study and literature review of nasal irrigation. Laryngoscope 2000 Jul; 110(7):1189-1193.

8. Talbot AR, Herr T, Parsons DS. Mucociliary clearance and buffered hypertonic saline solution. Laryngoscope 1997 April; 107(4):500-503.

9. Keojampa BK, Nguyen MH, Ryan MW. Effects of buffered saline solution on nasal mucociliary clearance and nasal airway patency. Otolaryngology- Head and Neck Surgery 2004; 131(5): 679682.

10. Boek WM, et al. Physiologic and hypertonic saline solutions impair ciliary activity in vitro. Laryngoscope 1999 March; 109(3): 396-399.

11. Min YG, et al. Hypertonic saline decreases ciliary movement in human nasal epithelium in vitro. Otolaryngol Head Neck Surg 2001 Mar; 124(3):313-316.

12. Homer JJ, et al. The effect of $\mathrm{pH}$ of douching solution on mucociliary clearance. Clin Otolaryngol 1999; 24:312-315. 